\title{
A Compact UWB MIMO Antenna for Portable Applications
}

\author{
Hao Hu, Zhigang Lu* \\ National Key Laboratory of High Power Vacuum Electronics, CPE of UESTC, Chengdu, China \\ Email: *lzhgchnn@uestc.edu.cn
}

How to cite this paper: $\mathrm{Hu}, \mathrm{H}$. and $\mathrm{Lu}$, Z.G. (2016) A Compact UWB MIMO Antenna for Portable Applications. Journal of Electromagnetic Analysis and Applications, 8, 240-246.

http://dx.doi.org/10.4236/jemaa.2016.810022

Received: September 18, 2016

Accepted: October 18, 2016

Published: October 21, 2016

Copyright $\odot 2016$ by authors and Scientific Research Publishing Inc. This work is licensed under the Creative Commons Attribution International License (CC BY 4.0).

http://creativecommons.org/licenses/by/4.0/

\begin{abstract}
A novel compact multiple-input-multiple-output (MIMO) antenna for portable ultrawideband (UWB) applications is presented. This antenna consists of two modified planar-monopole antenna elements with coplanar waveguides-fed printed on one side of the substrate. To enhance isolation and increase impedance bandwidth, a tree like stubs is placed on the ground plane at the $45^{\circ}$ axis. The measured results show that the MIMO antenna operates from $2.3 \mathrm{GHz}$ to $13 \mathrm{GHz}$, covering WLAN, WiMAX, and UWB. The low mutual coupling and low envelope correlation coefficient of less than 0.2 across the whole frequency band proved that this antenna was suitable for MIMO/diversity systems. Also, good performance of radiation patterns and the antenna's compact size make it a good candidate for portable devices.
\end{abstract}

\section{Keywords}

Multiple-Input-Multiple-Output (MIMO) Antenna, Pattern Diversity, Planar Monopole, Ultrawideband (UWB)

\section{Introduction}

Since the Federal Communications Commission (FCC) in the US opened the permit of 3.1 - $10.6 \mathrm{GHz}$ spectrum for applications with low power emission in 2002 [1], ultrawideband (UWB) became a rapidly growing technology. Multiple-input multipleoutput (MIMO) technology can be used to improve the capacity and link quality [2] [3]. Ultrawideband (UWB) system combined with MIMO technology can provide data rates more than $1 \mathrm{~Gb} / \mathrm{s}$ [4] [5]. However, one of the main challenges to the design of MIMO antennas for portable devices is low mutual coupling in small space [6] [7].

In recent years, many MIMO antennas have been proposed for UWB systems, including etching a ring slot in the ground plane [8] [9], inserting stubs between the two 
radiating elements [10], and good isolation was achieved by the tree-like structure between the two antenna elements. However, the operating frequency of the antenna in [4] is only from 3.1 to $10.6 \mathrm{GHz}$ and the size of the antenna in [5] can be improved.

In this paper, a low mutual coupling compact UWB MIMO antenna with a bandwidth from 3.1 to $12.6 \mathrm{GHz}$ is proposed. It has a compact size of $46 \mathrm{~mm} \times 46 \mathrm{~mm}$. Two planar-monopole antenna elements with coplanar waveguides-fed are placed perpendicularly to each other. A stub is placed on the ground plane to enhance isolation and bandwidth. Compared with the traditional UWB antenna, the proposed low mutual coupling compact UWB MIMO antenna combines with the advantages of orthorhombic structure and the decoupling structure to achieve a low mutual coupling and small size.

\section{Antenna Design}

\subsection{Antenna Configuration}

The geometry of the proposed antenna is shown in Figure 1, with an overall size of only $46 \times 46 \mathrm{~mm}$. It is designed on a on an FR4 substrate, with a thickness of $0.8 \mathrm{~mm}$, a permittivity of 4.4 , and a loss tangent of 0.02 . This antenna consists of two modified planar-monopole antenna elements which were staircase-shaped square radiators. CPW were used to fed antenna elements. The ground plane consists of a tree-like stub, which can efficiently enhance wideband isolation characteristics. The geometry and the dimensions of the proposed antenna is further illustrated in Figure 1 with details.

\subsection{Ioslation Stubs}

In this section, High Frequency Structure Simulator (HFSS) is carried out in order to study the effectiveness of the proposed tree-like structure.

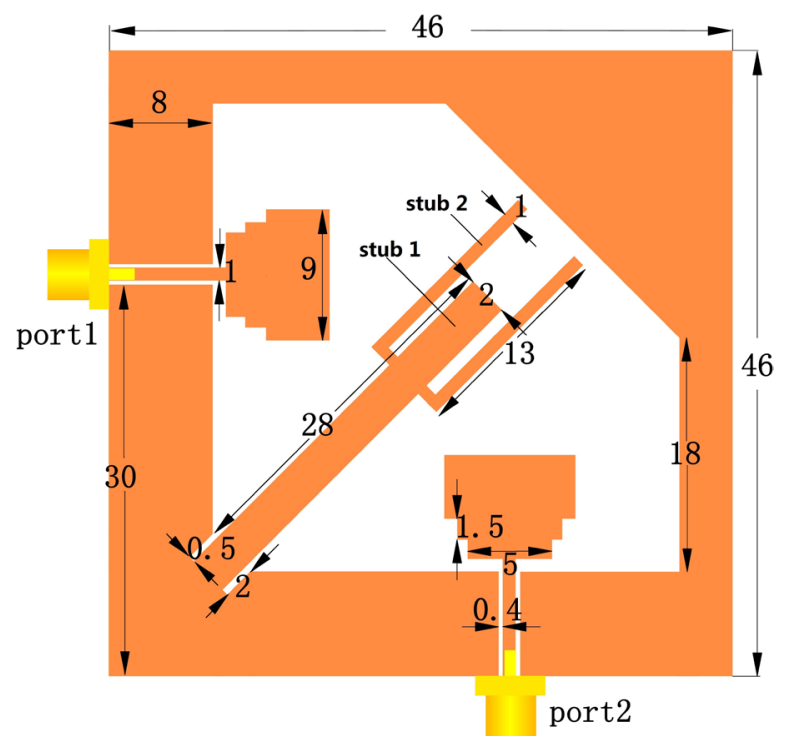

Figure 1. Configuration and parameters of proposed antenna (unit: $\mathrm{mm}$ ). 
The tree-like structure consists of two stubs. Stub 1 can be seen as a reflector and mutual coupling between the two modified planar-monopole antenna elements can be weakened. With stub 2, more resonances will be introduced, and a wideband isolation can be achieved. In Figure 2, we can see the isolation across the operating band improvement by introduce stub 1 and stub 2 .

\section{Experiment Results and Discussion}

\subsection{Impedance Performance}

An antenna prototype is fabricated, as shown in Figure 3. The S-parameters are measured with the Agilent E8363B vector network analyzer. Figure 4 shows the simulated and measured S-parameters of the proposed antenna. According to the measured

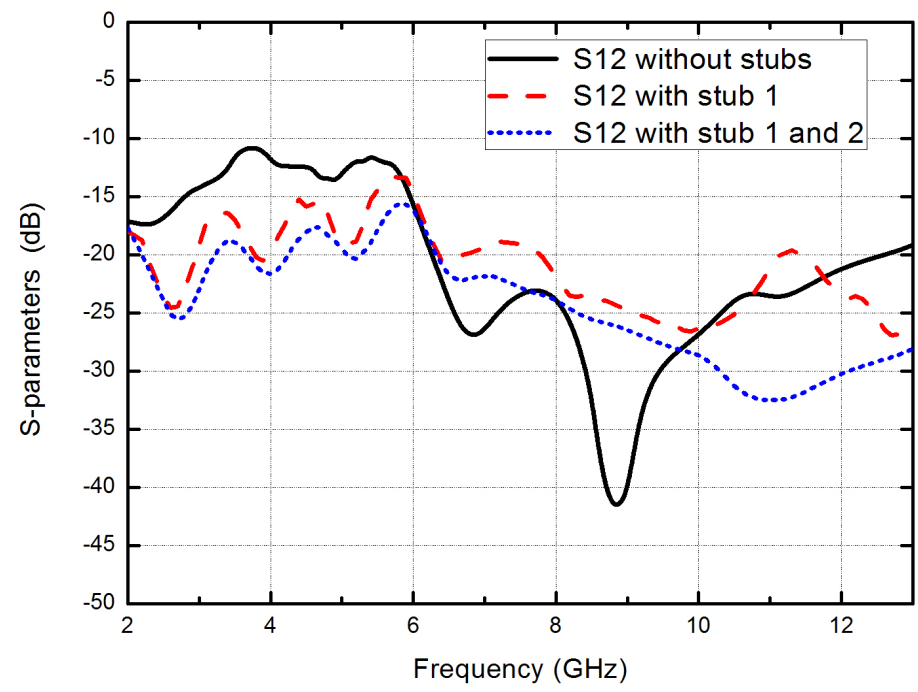

Figure 2. Simulated S12 when total number of stubs varies.

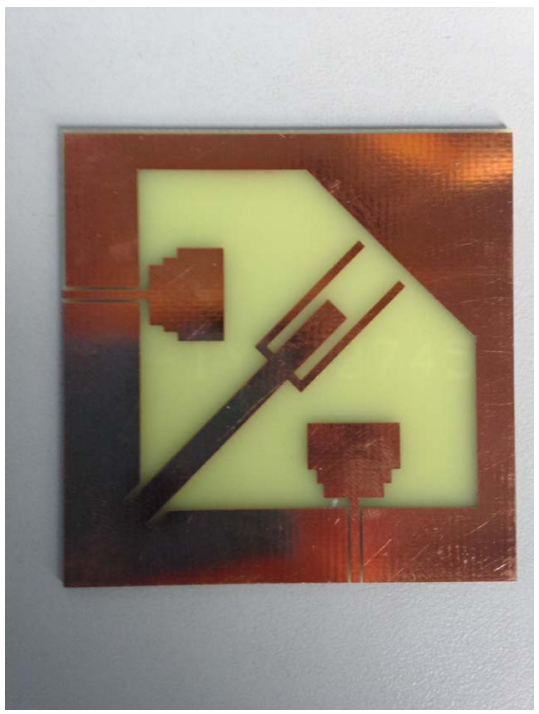

Figure 3. Prototype of proposed antenna. 
results, the impedance bandwidth (defined by a return loss of no less than 10-dB) is from $2.3 \mathrm{GHz}$ to $13 \mathrm{GHz}$. According to the measurement shown in Figure 4(b), the isolation between the two modified planar-monopole antenna elements is less than $20-\mathrm{dB}$. So that this antenna is suitable for portable devices.

\subsection{Radiation Performance}

The radiation patterns are measured with the anechoic chamber SATIMO Star Lab. Figure 5 shows the radiation patterns at $2.5 \mathrm{GHz}, 6.5 \mathrm{GHz}$, and $10.5 \mathrm{GHz}$, Port 1 is excited while Port 2 is terminated with a $50-\Omega$ load. The measurement gain of port 1 is plotted in Figure 6. The gains range from 3 to $6.5 \mathrm{dBi}$ across the frequency band from

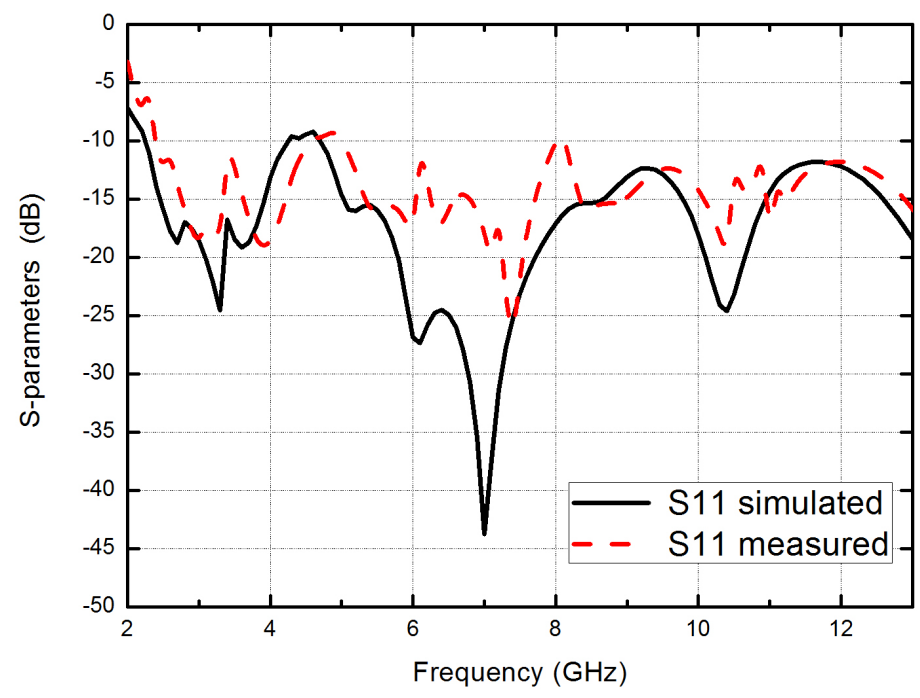

(a)

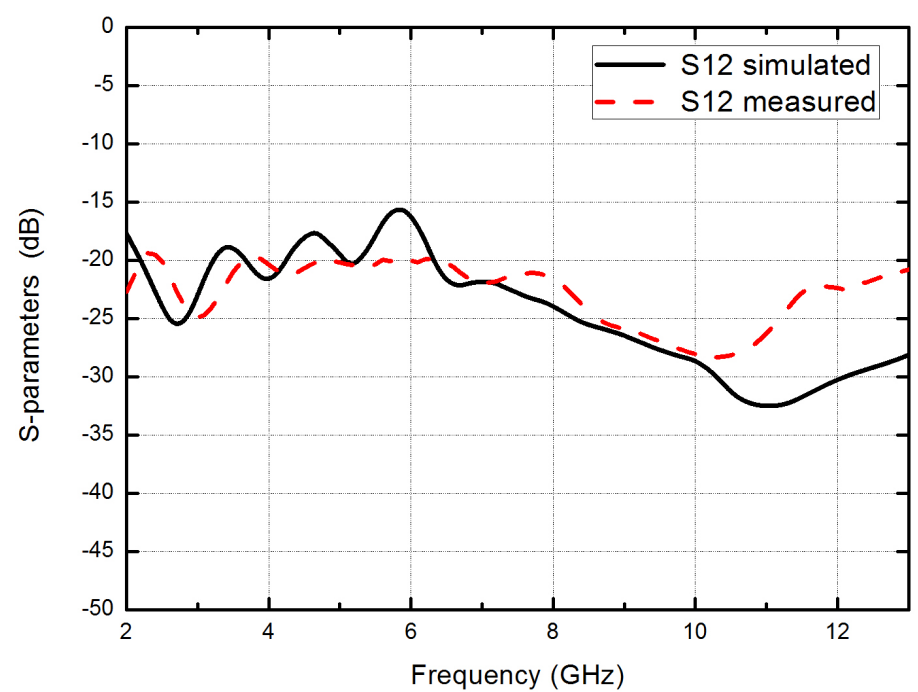

(b)

Figure 4. Measured and simulated S-parameters of proposed antenna: (a) S11; (b) S12 a. 


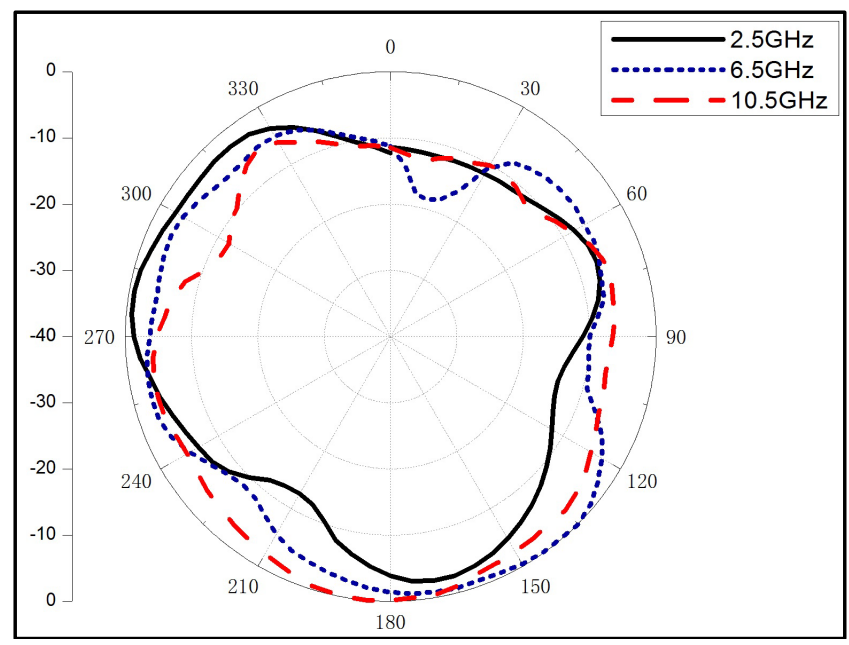

(a)

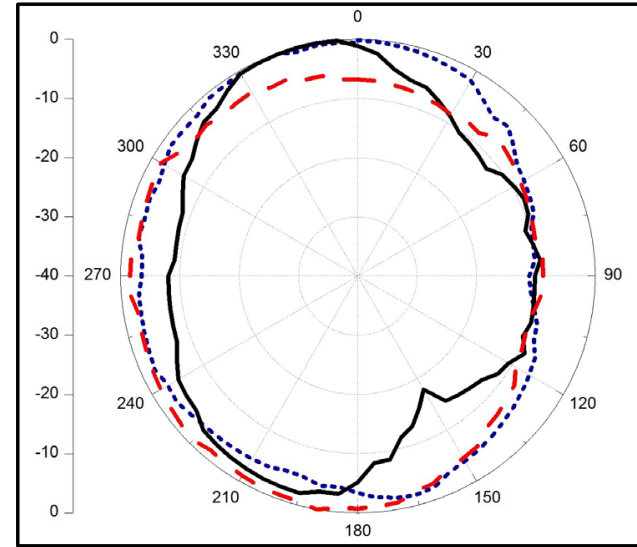

(b)

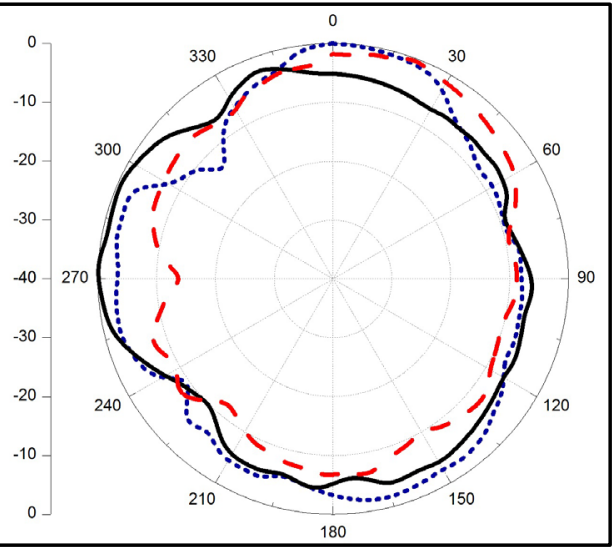

(c)

Figure 5. Measured radiation patterns of proposed antenna at $2.5 \mathrm{GHz}, 6.5 \mathrm{GHz}$, and $10.5 \mathrm{GHz}$ : (a) XY plane; (b) XZ plane; and (c) YZ plane.

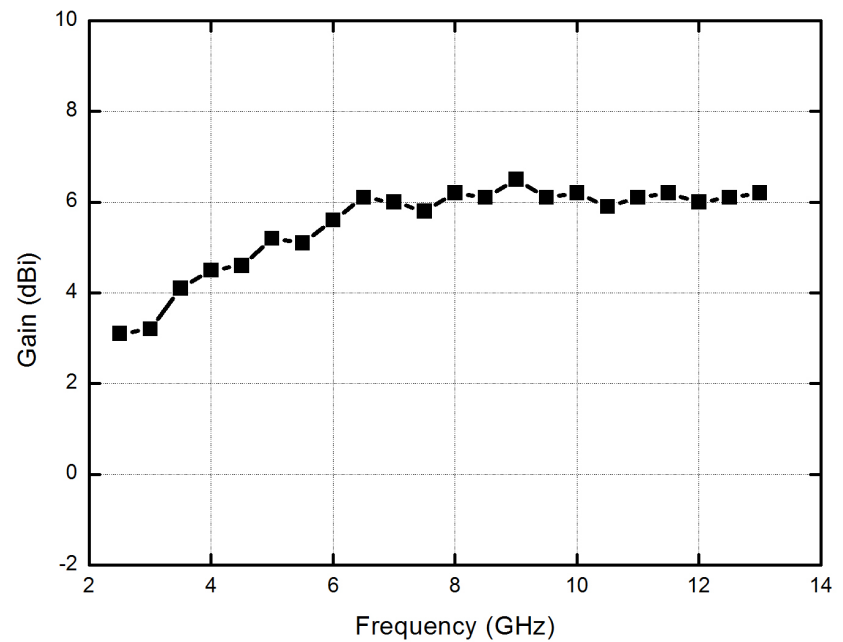

Figure 6. Measured gain of proposed antenna. 
$2.9-13 \mathrm{GHz}$. As shown in Figure 5, the proposed antenna has nearly Omni-directional radiation pattern, and it can be similar to traditional dipole antenna.

\subsection{Diversity Performance}

The envelope correlation coefficient (ECC) is an important parameter for evaluating the performance of the diversity system. The proposed antenna is below 0.01 across the whole operating frequency, shows that the antenna is suitable for a diversity system.

\section{Conclusion}

A dual port pattern diversity UWB antenna was presented. This antenna consists of two modified planar-monopole antenna elements and a tree-like stub is extended from the ground plane, which enhances the isolation coefficient more than 20-dB. An impedance bandwidth of $2.3 \mathrm{GHz}$ to $13 \mathrm{GHz}$ was obtained, and measurements of radiation patterns, antenna gain, and the ECC were shown. The antenna's compact size makes it suitable for portable MIMO/diversity applications.

\section{Acknowledgements}

Thanks for the guidance of Professor Zhigang Lu.

\section{References}

[1] Federal Communications Commission (2002) First Report and Order. Revision of Part 15 of Commission's Rules Regarding Ultrawideband Transmission Systems.

[2] Mietzner, J., Schober, R., Lampe, L., et al. (2009) Multiple-Antenna Techniques for Wireless Communications-A Comprehensive Literature Survey. IEEE Communications Surveys \& Tutorials, 55, 87-105. http://dx.doi.org/10.1109/SURV.2009.090207

[3] Kaiser, T., Zheng, F. and Dimitrov, E. (2009) An Overview of Ultra-Wideband Systems with MIMO. Proceedings of IEEE, 97, 285-312. http://dx.doi.org/10.1109/JPROC.2008.2008784

[4] Wei, K., et al. (2010) A Novel Hybrid-Fed Patch Antenna with Pattern Diversity. IEEE Antennas and Wireless Propagation Letters, 9, 562-565. http://dx.doi.org/10.1109/LAWP.2010.2051402

[5] Antonino-Daviu, E., et al. (2010) Ultrawideband Slot Ring Antenna for Diversity Applications. Electronics Letters, 49, 478-480. http://dx.doi.org/10.1049/el.2010.0262

[6] Zhang, S., Ying, Z., Xiong, J. and He, S. (2009) Ultrawideband MIMO/Diversity Antennas with a Tree-Like Structure to Enhance Wideband Isolation. IEEE Antennas and Wireless Propagation Letters, 8, 1279-1282. http://dx.doi.org/10.1109/LAWP.2009.2037027

[7] Ojaroudi, N. and Ojaroudi, M. (2013) A Novel Design of Triple-Band Monopole Antenna for Multi-Input Multi-Output Communication. Microwave and Optical Technology Letters, 55, 2158-2162. http://dx.doi.org/10.1002/mop.27579

[8] Mohammad, S. and Nezhad, A. (2010) A Novel Triband E-Shaped Printed Monopole Antenna for MIMO Application. IEEE Antennas and Wireless Propagation Letters, 9, 576-579. http://dx.doi.org/10.1109/LAWP.2010.2051131

[9] Zhang, S., Ying, Z.N., Xiong, J. and He, S.L. (2009) Ultrawideband MIMO/Diversity Antennas with a Tree-Like Structure to Enhance Wideband Isolation. IEEE Transactions on 
Antennas and Propagation, 8, 1279-1282. http://dx.doi.org/10.1109/LAWP.2009.2037027

[10] Wong, K.-L., Su, S.-W. and Kuo, Y.-L. (2003) A Printed Ultrawideband Diversity Monopole Antenna. Microwave and Optical Technology Letters, 38, 257-259.

http://dx.doi.org/10.1002/mop.11031

Submit or recommend next manuscript to SCIRP and we will provide best service for you:

Accepting pre-submission inquiries through Email, Facebook, LinkedIn, Twitter, etc.

A wide selection of journals (inclusive of 9 subjects, more than 200 journals)

Providing 24-hour high-quality service

User-friendly online submission system

Fair and swift peer-review system

Efficient typesetting and proofreading procedure

Display of the result of downloads and visits, as well as the number of cited articles

Maximum dissemination of your research work

Submit your manuscript at: http://papersubmission.scirp.org/

Or contact jemaa@scirp.org 